\section{A CASE OF SYRINGOMYELIA.}

By FRED. TRESILIAN, M.D., M.R.C.P.EDIN., Enfield.

MANY cases that are at first regarded as instances of progressive muscular atrophy are found on later examination to be cases of syringomyelia. This occurred in the case I wish to record; some years ago it was lectured on and exhibited at examinations as a case of progressive muscular atrophy. The exceptional features in this case are, first, the condition of the left shoulder-joint; secondly, the onset of symptoms much later in life than usually occurs; and, thirdly, a more rapid development of the disease.

W. P., aged 45, was first seen in October, 1898 . He first noticed wasting in the thenar muscles of the left hand about six or seven years ago, without any previous loss of power. Within the last twelve months he has observed a similar wasting in the right thenar muscles. His left shoulder has gradually become swollen to the size it is now within the last four or
five months, and the arm has swelled within the last few days. On examination there was found an enormous swelling around the left shoulderjoint, evidently containing fluid. It was not confined to the joint, but was evidently outside the synovial membrane, as it extended downwards to the insertion of the deltoid and into the axilla, backwards to the supraspinous fossa, and upwards to the clavicle and the upper part of the thorax. There was no pain. The whole of the arm was oedematous down
to the knuckles: He could move the arm freely, and had worked with it to the knuckles: He could move the arm freely, and had worked with it
up to the present. On moving the arm, which was abnormally mobile in all directions, there was distinct grating at the shoulder-joint, with clicking, as from the rubbing of bare or broken bone. There was nothing similar in either the elbow-joints or wrist-joints. Both hands were in a condition of main en griffe, the left being most so, with wasting of the interossei and thenar and hsp pthenar eminences. Sensibility to touch was normal everywhere. Sensibility to pain was lost over the left upper extremity, the shoulder, the side of the neck, and the left side of the thorax. Thermal sensibility was lost over exactly the same region. On the right side the sensations appeared to be normal, save around the no weakness or rigidity of the legs, and no inco-ordination. There was no weakness or rigidity or the legs, and no inco-ordination. The knee. ankle clonus. Nystagmus was pri se had distinct but not prolonged showed the characteristic changes or myopia, and the fundi were otherwise normal. The laryngoscopo shower weak abduction of the left vocal cord, it was not immobile, but was much less brisk in its movement than its fellow.

I made him rest from work, and in a few days the cedema of the arm went down considerably, and then I could see that the small muscles of the left hand were much more atrophied than those of the right. I aspirated the shoulder-joint, and got away about 6 ounces of gelatinous blood-stained fluid, which was only a small portion of what the joint contained, but though I moved the needle about in various directions no more would flow away. I think it must have been loculated by adhesions. The operation gave him no pain whatever, and he did not feel the introduction of the needle. He returned to his work, which he refused to give up, as he felt able to do it satisfactorily, and I have only seen him once since, when he was in exactly the same condition.

This man had noticed no symptoms in childhood. He never had any condition of whitlows, or ulcers, or chilblains, though he remarked since the onset of the disease, that if he burnt or cut his left hand it did not give him pain. The left shoulder-joint exhibited a condition exactly similar to that of advanced "Charcot's disease" as seen in tabes. There was evidently disorganisation of the joint, with destruction of the head of the humerus. This did not interfere with the power of the arm.

It will be interesting to watch if his laryngeal abductor paresis becomes absolute, and if any other signs of implication of the medulla are exhibited in the progress of the disease.

\section{THE TREATMENT OF MALARIAL FEVERS BY THE INUNCTION OF CREOSOTE.}

By Major A. O. FITZGERALD, R A.M.C., L.R.C.P.I., Medical Officer in Charge of the Station Hospital, Belgaum.

Mr attention was first directed to the utility of creosote inunction by a note in the British MEDICAL JoURnaL of January 4th, 1896, by Surgeon-Lieutenant Leonard Rogers, M.B., F.R.C.S. I have not strictly followed the method or dosage mentioned in his publication, but have varied them as follows : Pure beechwood creosote, 15 to 20 minims for a child of I year, or 30 to 60 minims for an adult, was mixed with an equal quantity, or more, of olive oil, and rubbed, for from five to ten minutes, over the chest, abdomen, axillæ, and sides. The oil was only employed to counteract the tingling and burning occasionally produced by the creosote.

The accompanying table contains cases of malarial fevers alone, as I wish to draw attention to the specific action the treatment appears to have in them. Their number, I am aware, is too limited to prove anything absolutely; but as equally good results were obtained in many more cases during the past year, notes of which it was impossible to take owing to pressure of work, I think it permissible to forward this report now.

A glance at the table will show that the results are remarkably uniform. In Class I, in the majority of cases, the usual remedies had been tried, and were continued afterwards, so the creosote may be looked on as merely an adjuvant. In Class II the Cases XIII and XVI to XXIII were treated with creosote as soon as they came into hospital, and nothing else was given, so that a secondary place cannot be given to it in these while, in Class III the results were so striking in cutting short the disease and preventing recurrences, that $I$ give the first four in detail as typical examples of the class of case in which the treatment may be found most useful. Before doing so I may refer briefly to a few of the cases in the other classes.

\section{Crass I.}

CASE III.-The usual treatment had utterly failed. The temperature remained between $103^{\circ}$ and $105^{\circ} \mathrm{F}$. The patient was getting worse. At first mxv ter die were ordered first, but as the effects were not marked the dose was increased to 3ss. ter die. The husband was too energetic, and rubbed it in nine times on June 7 th, 1896, but no unpleasant symptoms followed, and 3ss. ter die was continued until the temperature fell to normal. The tongue began to clean, and sleep was obtained after the first inunction, and it was very remarkable how the appetite returned, and the patient asked for food on the second day of treatment.

CASE IV.-This patient had just come down country saturated with malaria Helived in quarters by himself, and when seen first was semi-delirious; all his servants were sick, and he had no one to look after him or administer medicine. Under these conditions the value of the treatment is well exemplified : 3 ss was rubbed in twice on evening of June roth, 1896. He fell asleep shortly after, and continued asleep well into the next day without any other treatment. On the evening of irth he felt better than he had tion for a week. and had no recurrence during that reme.ned in the stato continue taking quinine, arsenic, iron, and strychnine owing to his to continue taking

\section{Crass II.}

CASE XV.-An old soldier, cachectic and emaciated, had been subject to frequent bad attacks of ague, which sometimes assumed a continued his cachectic condition. He is now fat, strong, and with a good colour his cachectic condition. He

Class III.

The dosage in this class was out of proportion larger than in the others, and to this may be due the fact that the results are more striking, the conclusion being, I think, that the dose for adults might be greatly increased with advantage. The first four I will now give in detail.

CASE I. -A. D. F., aged 1 , was suffering from continued malarial fever. and had had no sleep for at least twenty-tour hours. He had been previously treat ex with ordinary remedies. On June 6th, 1896, vomiting had of quinine were rejected at once. At 9 P.M. the temperature was $103^{\circ} \mathrm{F}$. of quinine were rejected at once. At 9 P.M. the temperature was $103^{\circ} \mathrm{F}$., tity of olive oil was rubbed in over the chest and sides. The effect was practically instantaneous, the spasms became gradually less, the patient practically instantaneous, the spasms became gradually less, the patien temperature had fallen to ed ind the easy sleep. In half an hour the effect continued throughout the night, and the vomiting having ceased he was able to take his food. On June 7 th, at 7.30 A.M., the temperature was ror $^{\circ} \mathbf{F}$., but none of the graver symptoms had returned. The same quantity of creosote and oil was rubbed in, after which the temperature gradually fell. The patient was quite comfortable all day, sleeping at intervals. and finally sank into a deep sleep at 7 P.M. ; he scarcely stirred until the
following morning, when the temperature was normal. There was no recurrence, and no further treatment was required.

CASE VI.-E. F. G., aged 4 years Ir months, was suffering from malariaI fever, with bilious vomiting and purging, which prevented any medicine or food being retained. The temperature rose gradually for three days, until on the morning of June 24 th, 1896 , it was ro4 ${ }^{\circ} \mathrm{F}$. Creosote mxv with an equal quantity of olive oil was rubbed in at $7.3^{\circ}$ A.M. . after which she slept an hour and a-half. The temperature continued to rise until a 6 P.M. it was ro $5^{\circ} \mathrm{F}$. : $\mathrm{mxxv}$ of creosote with oil were then rubbed in. This relieved all the symptoms, and the patient slept well the whole night. The temperature gradually fell to normal on June 27 th without the July ist she was in her usual health. There was no recurrence.

CASE IX.-E. F., aged 4, was suffering from malarial fever of an intercase 1X. - . . ., aged 4, was surfering from malarial fever of an intermittent tertian type, and was taking liquor arsenicalis and quinine with diaphoretics and potassium bromide. At 2 P.M. On July 31 st, 1896, she was very restless and becoming delirious. She was apparently suffering much pain. The temperature, taken in the groin, was $103.4^{\circ} \mathrm{F}$., but was proonce over the chest, abdomen, and sides, and as I rubbed the child gradu- 